\title{
YouTube as a source of information for water treatments
}

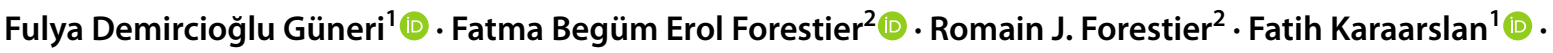 \\ Ersin Odabaşi ${ }^{1}$
}

Received: 4 November 2021 / Revised: 21 December 2021 / Accepted: 25 December 2021 / Published online: 30 January 2022

(c) The Author(s) under exclusive licence to International Society of Biometeorology 2021

\begin{abstract}
The purpose of the study was to investigate the quality and reliability of YouTube videos as a source of information in water treatments. We searched videos on YouTube (www.youtube.com) using the following keywords: "health resort medicine," "spa treatment," "spa therapy," "hydrotherapy," "thermal medicine," "balneology," and "balneotherapy" on June 17th, 2021. The global quality scale (GQS) was used to evaluate the quality of the videos. The assessment of reliability was evaluated using the modified DISCERN tool. Some other video parameters and sources of the videos were also recorded. One hundred twenty-one (121) videos were analyzed. The most common video source was advertisement (46.3\%). GQS and modified DISCERN median scores were generally low. They were superior for "hydrotherapy" and "balneotherapy" and were also higher in videos uploaded by health-related persons or organizations (physicians, health-related professionals, and healthrelated websites). A statistically significant positive correlation was found between investigated parameters (like view ratio, number of likes, video power index, video length) and GQS. Only video length was correlated with modified DISCERN for investigated parameters. The median video power index scores were statistically higher for "spa therapy" and "spa treatment." The YouTube content linked with water treatments has poor quality and reliability most of time. The hydrotherapy and balneotherapy keywords have the best quality and reliability.

We think that designers of water treatment videos should involve health professionals more often so that the content of their video will better explain the details of medical conditions or interventions.

The scientific experts should ensure a consensus in terminology to straighten the awareness of water treatments for patients and physicians.
\end{abstract}

Keywords Health resort medicine $\cdot$ Spa therapy $\cdot$ Balneotherapy $\cdot$ Water treatments $\cdot$ YouTube

\section{Introduction}

Usage of water for treatment is thought to be as old as humanity. Even though the invention of the analgesic drugs had caused a limitation in the common use of water treatments, the attention on these treatments has increased again since the analgesic drugs are not fully effective in releasing the pain, and they also have reported side effects (Bender et al. 2005).

Fulya Demircioğlu Güneri

fuliad@hotmail.com

1 Department of Medical Ecology and Hydroclimatology, Gülhane Training and Research Hospital, University of Health Sciences, Ankara, Turkey

2 Centre de Recherce Rhumatologique Et Termal, Aix Les Bains, France
Term of health resort medicine (or spa treatment) is proposed to define the whole of the medical treatment modalities with promotion, prevention, and rehabilitation purposes in health resorts (Gutenbrunner et al. 2010). Balneotherapy, hydrotherapy, and climatotherapy were specified as "core elements" in health resort medicine. Hydrotherapy modalities are delivered with plain water, whereas balneotherapy modalities are performed with natural sources like spring water, peloids (muds), and gases (Antonelli et al. 2018). The other treatment modalities in health resorts or spa centers are exercise, relaxation therapies, and physical therapies (StierJarmer et al. 2015).

Medical spa treatments are mainly used for musculoskeletal and dermatologic disorders (Bernetti et al. 2018; Huang et al. 2018). In a recent review, different in vitro studies analyzed the potential effect of mineral water, demonstrating their anti-inflammatory, antioxidant, and 
chondroprotective properties in OA cartilage, synoviocytes, chondrocytes, and osteoblast and osteoclast cultures. (Cheleschi et al. 2021). There are a lot of studies to show the beneficial effects of spa treatments in several diseases such as osteoarthritis (Fioravanti et al. 2012; Forestier et al. 2010), chronic low back pain (Constant et al. 1995, 1998), fibromyalgia (Dönmez et al. 2005), rheumatoid arthritis (Franke et al. 2007; Franke et al. 2000), ankylosing spondylosis (van Tubergen et al. 2001), atopic dermatitis and psoriasis (Leaute-Labreze et al. 2001; Borroni et al. 2013) in literature. Even though balneotherapy is regarded as an effective complementary treatment modality in managing some rheumatic diseases, the methodological flaws in studies prevent making a particular judgment about the effectiveness of water treatments (Verhagen et al. 2012). Yet, these treatments have maintained their popularity for centuries, which may be related to overall patient satisfaction.

Online research is an important part of everyone's daily life in the internet age. Many people use the Internet to access health information (Kocyigit et al. 2019). The use of the Internet as a tool for information about health problems has been demonstrated for half of the US population. (Amante et al. 2015). But there is no control mechanism to consider the accuracy of the online-based information, leading to the misinformation effect (van Uden-Kraan et al. 2009).

For monitoring people's interests in different topics in medicine, the Google trend is used in researches increasingly (Teng et al. 2017; Yang et al. 2017; Kardeş 2019a, b). Data obtained from Google Trends are useful in predicting disease occurrence and outbreaks (Mavragani and Ochoa 2019). Recently, Google Trend analyses were performed to reveal the people's interest in balneology during COVID 19 pandemic. (Kardeş 2021; Maccarone et al. 2021). On the other hand, YouTube analyses evaluate the content and accuracy of the videos about medical issues.

One of the most used and second popular websites for sharing video worldwide is YouTube, with more than 2 billion users (YouTube for press 2020). Since it is easy to use and does not require payment to watch or upload videos, it can be an essential tool for reaching health-related information (Ozsoy-Unubol and Alanbay-Yagci 2021).

In literature, the studies evaluating the quality, content, and reliability of the YouTube videos linked with health concerns have increased in number (Singh et al. 2012; Kocyigit et al. 2019; Esen et al. 2019; Garg et al. 2015; Gul and Diri 2019, Loeb et al. 2019; Erdem and Karaca 2018; Ferhatoglu et al. 2019; Gaş et al. 2019; Ozsoy-Unubol and AlanbayYagci 2021; Tolu et al. 2018; Kocyigit et al. 2019). It was remarked that there are good-quality videos with accurate information as well as poor-quality videos which may contain bias and commercial intentions (Madathil et al. 2015).
YouTube can be a tool to disseminate truthful information about water treatments explaining the treatment's purpose, benefits, application methods, indications, and contradictions. Thus, people who want to use this kind of treatment would know better what to expect by watching high-quality videos. Our study is the first to search video quality and reliability about water treatments on YouTube.

The primary aim of this study was to investigate the quality and reliability of YouTube videos in English as a source of patient information in this field. The secondary aim was to compare features (searched with different terms) and the sources of the videos and show if there is a correlation between their quality and reliability scores.

\section{Methods}

This was a descriptive, cross-sectional, observational study. We evaluated the quality and reliability of the videos about water treatments broadcasted on YouTube, accessible from Turkey, on June 17th, 2021.

\section{Ethics statement}

Ethics committee approval was not required since our study did not include any human participants or animals and the videos were open public. The same path was followed by similar studies in the literature (Tolu et al. 2018; Kocyigit et al. 2019).

\section{YouTube searches}

We searched videos on YouTube (www.youtube.com) using the following keywords: "health resort medicine," "spa treatment," "spa therapy," "hydrotherapy," "thermal medicine," "balneology," and "balneotherapy" on June 17th, 2021. The first 50 videos were evaluated for each of the keywords (with a total number of 350) by two researchers (FDG, FBEF) specialized physicians in Thermal Spa Medicine. The videos that are digressive, irrelevant, duplicate, and in a language other than English were excluded.

The YouTube videos are supposed to be sorted by relevance. So, the most relevant videos are displayed at the top of the page. However, since the investigators (FDG, FBEF) live in different countries (Turkey and France), the featured videos are sorted into different lines. So, while watching the videos, we used the "screen share" option of the Zoom application and went over one screen to avoid confusion.

\section{Quality assessment}

The two researchers assessed the contents of the videos. Global Quality Scale (GQS) was used to evaluate the videos 
(Bernard et al. 2007). GQS is a five-point scale that varies from 1 (lowest score) to 5 (highest score) (Table 1).

This scale enables grading the videos by means of their flow, ease of use, and quality. According to this, total scores with 4 or 5 points indicate high quality, 3 points indicate moderate quality, and 1 or 2 points indicate low quality. When there was a discrepancy between researchers about scoring, the video was discussed and reassessed to obtain a consensus (Bernard et al. 2007).

\section{Assessment of reliability}

DISCERN tool was used to assess the reliability of the YouTube videos. DISCERN is a standardized set of criteria used for evaluating the quality of health information (Charnock et al. 1999). We used 5-point modified DISCERN tool to assess the reliability of the videos. This tool was previously utilized in several studies with the same purpose (Singh et al. 2012; Kocyigit et al. 2019; Esen et al. 2019; Garg et al. 2015; Gul and Diri 2019). This scale comprises five yes/no questions. 1 point is given for each "yes" and 0 points for the "no" answer; the maximum total score is 5 (Table 2).

\section{Video features}

The number of the views, the total number of likes, dislikes, and video length, and duration since upload date were recorded. We looked for a correlation between investigated features and the quality and reliability scores of the videos. Also, we calculated "like ratio" ((number of likes/ number of likes + number of dislikes $) \times 100)$ and "video power index" (VPI) (like ratio*view ratio/100). Like ratio and VPI were used for the popularity of the videos (Erdem and Karaca 2018).

\section{Sources of videos}

The sources of the videos were categorized as physicians, non-physician health professionals, health-related websites, professional organizations/associations, patients, trainers, TV programs, and independent users.
Table 2 Modified DISCERN scoring system

\begin{tabular}{lc}
\hline Questions & Score \\
\hline Are the aims clear and achieved? & $0-1$ \\
$\begin{array}{l}\text { Are reliable sources of information used? (i.e., publication } \\
\text { cited, speaker is an epidemiologist or medical professional) }\end{array}$ & $0-1$ \\
$\begin{array}{l}\text { Is the information presented balanced and unbiased? } \\
\text { Are additional sources of information listed for patient refer- }\end{array}$ & $0-1$ \\
$\quad$ ence? & $0-1$ \\
Are areas of uncertainty mentioned? & 0 \\
\hline
\end{tabular}

1 point is given for each "yes" and 0 point for the "no" answer

\section{Statistical analysis}

The statistical analyses were performed on IBM version 22.0 (IBM Corporation, Armonk, NY, USA). While continuous variables were presented as means + standard deviations, categorical data were presented as numbers and percentages. Kolmogorov-Smirnov test was used to check the normality of data. Kruskal-Wallis test and post hoc Bonferroni-corrected Mann Whitney $U$ test were used in between-group analysis since data were not distributed normally. $P$ values less than 0.0045 were considered significant. Non-parametric Spearman's rho correlation analysis was performed for correlations. The reliability and correlation analyses were performed using Cohen's kappa test and non-parametric Spearman's rho correlation analysis, respectively. $P$ values less than 0.05 were considered significant.

\section{Results}

We watched 50 videos for each keyword with a total number of 350. Two hundred twenty-nine (229) videos were excluded: 198 were irrelevant, 6 were duplicate, and 25 were in a language other than English. A total of 121 videos were analyzed (Fig. 1).

The general video characteristics are presented in Table 3.

Table 1 Global Quality Scale scoring system

\begin{tabular}{ll}
\hline Questions & Score \\
\hline Poor quality, poor flow of the site, most information missing, not at all useful for patients & 1 \\
Generally poor quality and poor flow, some information listed but many important topics missing, of very limited use to patients & 2 \\
Moderate quality, suboptimal flow, some important information is adequately discussed but others poorly discussed, somewhat useful for & 3 \\
patients & \\
Good quality and generally good flow, most of the relevant information is listed, but some topics not covered, useful for patients \\
Excellent quality and excellent flow, very useful for patients
\end{tabular}


Fig. 1 Flow diagram

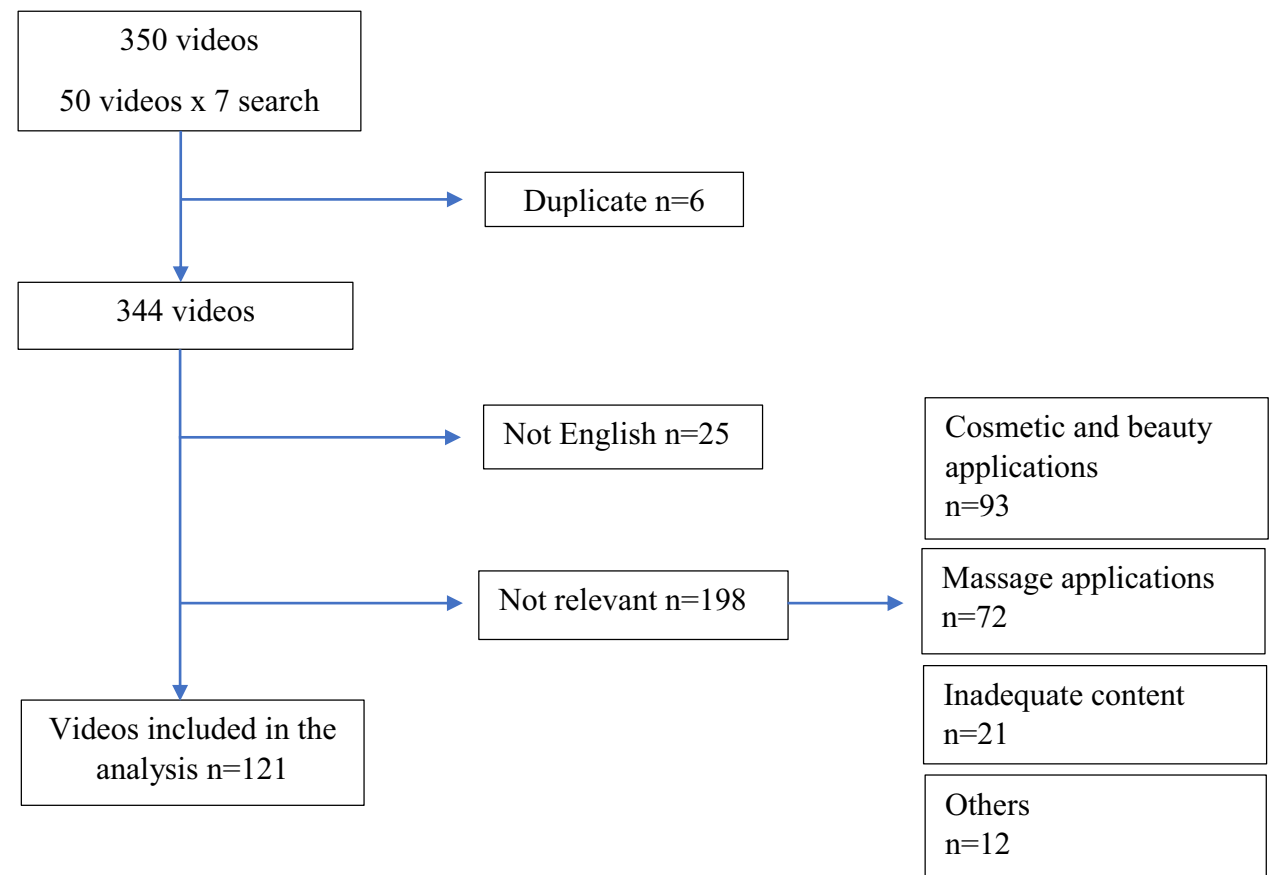

Table 3 The general video characteristics

\begin{tabular}{lc}
\hline Video features & Median $(\min -\max )$ \\
\hline Video length $(\min )$ & $3.2(0.16-122.18)$ \\
View count $(n)$ & $2725(7-11,990,028)$ \\
View ratio & $2.3(0.01-10,135.27)$ \\
Duration since upload (days) & $1214(8-5236)$ \\
Like count $(n)$ & $15(0-47,000)$ \\
Like index & $97(0-100)$ \\
Unlike count $(n)$ & $0(0-5200)$ \\
Video power index (VPI) & $1.48(0-8330)$ \\
Global quality scale (GQS) & $2(1-5)$ \\
Modified DISCERN & $2(1-5)$ \\
\hline
\end{tabular}

\section{Quality and reliability}

The median quality and reliability scores of the videos were generally low. We found that $16.5 \%(n=20)$ of the videos were high quality, $20.7 \%(n=25)$ intermediate quality, 24\% $(n=29)$ were generally poor quality, and $38 \%$ $(n=46)$ poor quality according to GQS (Fig. 2).

The GQS and modified DISCERN median scores were found significantly superior for "hydrotherapy" and "balneotherapy" keywords in comparison with others $(p<0.001)$ (Table 4).

When we analyzed the relationship between GQS and modified DISCERN median scores, and the sources, we found a significant difference in favor of the videos uploaded by physicians, health professionals, and health-related websites in general. The GQS and modified DISCERN median scores were statistically higher for the videos uploaded by physicians than advertisement videos ( $p<0.001$ and $p<0.001$, respectively). The GQS median scores were higher for videos uploaded by health professionals compared to other sources as patients, TV programs, independent users, and advertisements (respectively $p=0.010, p=0.013, p=0.05$, and $p<0.01$ ). Also, the modified DISCERN median scores of health professionals were superior to the score of the patients, independent users, and advertisements videos statistically ( $p=0.010, p=0.011$, and $p<0.001$, respectively) (Table 5).

A statistically significant positive correlation was found between GQS $(r=0.226, p=0.013 ; r=0.216, p=0.004$; $r=0.210, p=0.021 ; r=0.210$ and $p=0.021$ respectively.) and the investigated parameters (view ratio, like count, video power index, video length). Modified DISCERN was positively correlated with video length only $(r=0.312$, $p<0.013)$.

\section{Video features}

When we compared the treatment modalities with each other, we found no statistically significant difference in video length, duration since upload date, and like index median values. However, the number of views, like and dislike count, and the view ratio were statistically different $(p<0.001)$. In addition, the median video power index of the "spa therapy" and "spa treatment" videos was found 
Fig. 2 The general quality of the videos

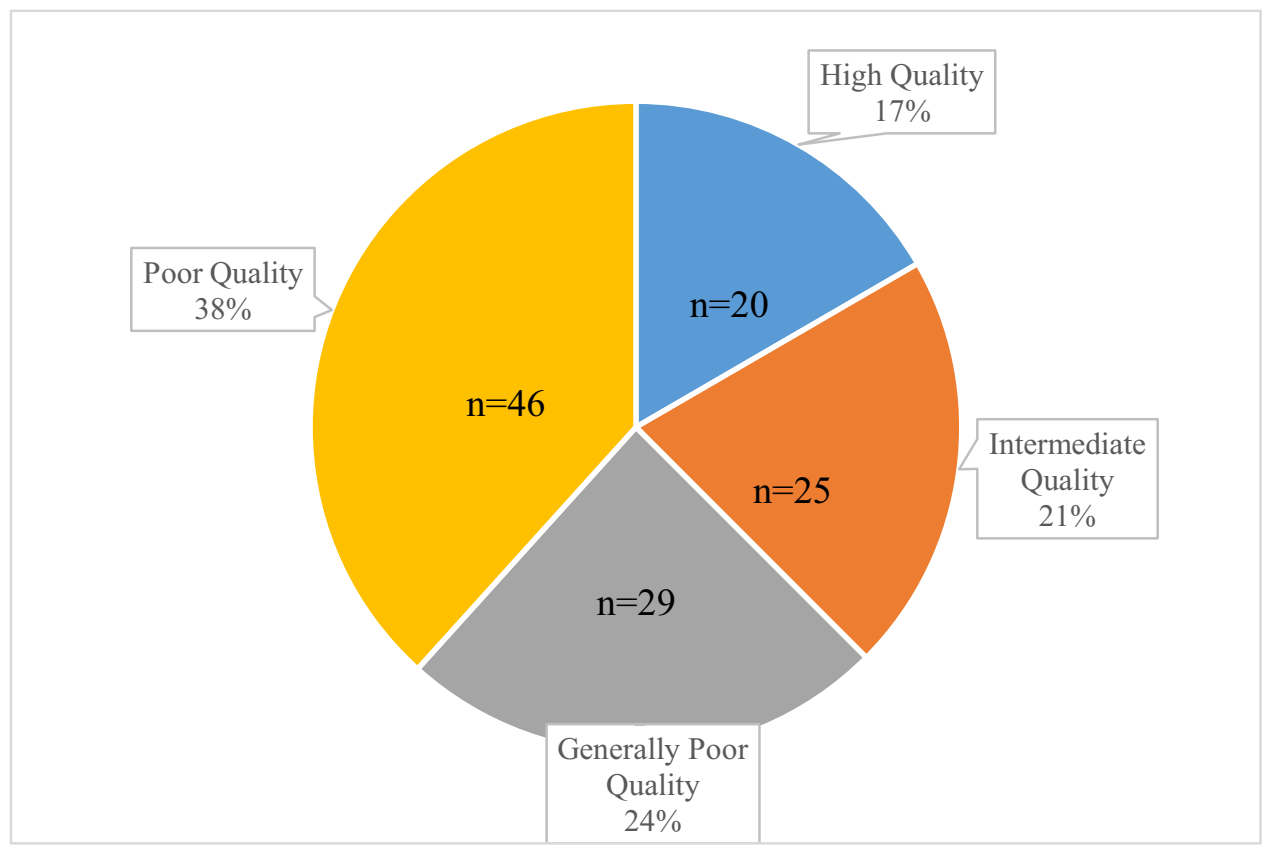

significantly higher compared to other keywords $(p<0.001)$ (Table 4).

\section{Video sources}

The distribution of video sources is presented in Fig. 3 . Fifty-six of the 121 videos analyzed were an advertisement. The other sources of the videos were non-physician health professionals $(n=25)$, physicians $(n=11)$, and independent users $(n=10)$.

The sources of the videos were mostly advertisements for health resort medicine (89.3\%), spa therapy (60\%), and balneology (75\%). On the other side, we found that $59.9 \%$ of hydrotherapy and $36.8 \%$ of balneotherapy videos were uploaded by health-related websites, physicians, or nonphysician health professionals $(p<0.001)$ (Table 4$)$.

\section{Discussion}

With this cross-sectional study, we observed that the quality and reliability were generally low; some good-quality ones were mainly designed by doctors and health professionals. Balneotherapy and hydrotherapy were found to be the best keywords.

\section{Quality}

According to our results, the quality of videos was generally low. Our findings are consistent with some of the previous studies of similar design in this regard (Knösel and Jung 2011; Singh et al. 2012; Kocyigit et al. 2019). The "hydrotherapy" and "balneotherapy" keywords provided better-quality videos. Since the videos uploaded by physicians, health-related professionals, and health-related websites had good quality according to GQS scores, the superiority in "quality of hydrotherapy videos" may be explained by the majority (59.9\%) of health-related sources. Besides, we may speculate that hydrotherapy and balneotherapy are the most preferred terms in this field among health professionals. It is not surprising that terminology widely used in medical and research fields correlates with higher quality videos.

\section{Reliability}

The overall reliability was also low. However, in the same way as quality scores, the videos uploaded by physicians, other health professionals, and health-related websites were the most reliable. Similar results were shown in some other studies (Singh et al. 2012; Sajadi and Goldman 2011).

Since the quality and reliability of the analyzed videos are generally low, we think that the support of health professionals is necessary to eliminate the lack of accurate information about water treatments.

The most reliable videos were also the ones using "hydrotherapy" and "balneotherapy" keywords. The contents' poor quality and reliability led us to think that there may be confusion in terminology used to define the water treatments. Even though the relevant scientists offered a proposal to define a specific terminology (Gutenbrunner et al. 2010), it is seen that the problem still exists. Thus, we guess that this terminology problem limits the recognition and development of these therapies. 
Table 4 Between group (different treatment modalities) comparison of the investigated parameters

\begin{tabular}{|c|c|c|c|c|c|c|c|c|}
\hline $\begin{array}{l}\text { Video features } \\
\text { Median (min- } \\
\text { max) }\end{array}$ & $\begin{array}{l}\text { Health resort } \\
\text { medicine } \\
(n: 28)\end{array}$ & $\begin{array}{l}\text { Balneotherapy } \\
(n: 19)\end{array}$ & $\begin{array}{l}\text { Spa therapy } \\
(n: 5)\end{array}$ & $\begin{array}{l}\text { Hydrotherapy } \\
(n: 45)\end{array}$ & $\begin{array}{l}\text { Thermal medi- } \\
\text { cine }(n: 3)\end{array}$ & $\begin{array}{l}\text { Balneology } \\
(n: 16)\end{array}$ & $\begin{array}{l}\text { Spa treatment } \\
(n: 5)\end{array}$ & $P^{*}$ \\
\hline View count & $\begin{array}{c}3028(81- \\
1,246,924)\end{array}$ & $\begin{array}{l}451(22- \\
509,125)\end{array}$ & $\begin{array}{c}10,000(163- \\
721,000)\end{array}$ & $\begin{array}{l}7289(89- \\
11,990,028)\end{array}$ & $105(17-6090)$ & $83(7-4118)$ & $\begin{array}{c}309,774 \\
(54,506- \\
3,757,980)\end{array}$ & $<0.001 *$ \\
\hline View ratio & $5.9(0.07-690)$ & $\begin{array}{c}0.39(0.09- \\
263.9)\end{array}$ & $\begin{array}{c}15.9(0.9- \\
249.2)\end{array}$ & $\begin{array}{c}4.5(0.11- \\
10,135.2)\end{array}$ & $\begin{array}{l}0.23(0.19- \\
1.56)\end{array}$ & $\begin{array}{l}0.23(0.01- \\
2.38)\end{array}$ & $\begin{array}{c}229.3(22.7- \\
4194.2)\end{array}$ & $<0.001 *$ \\
\hline $\begin{array}{l}\text { Video length } \\
\text { (minute) }\end{array}$ & $\begin{array}{l}3.07(0.17- \\
57.14)\end{array}$ & $\begin{array}{l}3.14 \\
(1.07-25)\end{array}$ & $2.3(1.1-3.3)$ & $\begin{array}{l}3.4(0.16- \\
62.9)\end{array}$ & $6(3.3-16.1)$ & $2.5(0.18-122)$ & $5(3.2-68.4)$ & $0.416^{*}$ \\
\hline $\begin{array}{l}\text { The duration } \\
\text { since upload } \\
\text { (day) }\end{array}$ & $\begin{array}{l}1151.5 \\
(48-4762)\end{array}$ & $\begin{array}{l}1298 \\
(53-2757)\end{array}$ & $\begin{array}{l}706(181-31- \\
52)\end{array}$ & $\begin{array}{l}1267 \\
\quad(76-4575)\end{array}$ & $444(88-3905)$ & $1468(8-5236)$ & $\begin{array}{l}1240(896- \\
3152)\end{array}$ & $0.915^{*}$ \\
\hline Like count & $12(0-826)$ & $5(0-8300)$ & $120(4-2600)$ & $44(0-24,000)$ & $1(0-13)$ & $1(0-13)$ & $\begin{array}{c}1300(506- \\
47,000)\end{array}$ & $<0.001 *$ \\
\hline Like index & $97.7(0-100)$ & $100(0-100)$ & $95.5(80-100)$ & $96.7(0-100)$ & $92.8(0-100)$ & $100(0-100)$ & $\begin{array}{l}94.6(85.4- \\
96.3)\end{array}$ & $0.831^{*}$ \\
\hline Dislike count & $0(0-50)$ & $0(0-184)$ & $5(0-222)$ & $1(0-5200)$ & $0(0-1)$ & $0(0-2)$ & $123(31-1800)$ & $<0.001 *$ \\
\hline VPI & $1.4(0-650.6)$ & $\begin{array}{l}0.31 \\
(0-258.5)\end{array}$ & $15.3(0-237.9)$ & $\begin{array}{l}4.04 \\
\quad(0-8330.4)\end{array}$ & $0.24(0-1.45)$ & $0.12(0-2.38)$ & $\begin{array}{c}195.8(21.5- \\
4039.4)\end{array}$ & $<0.001 *$ \\
\hline GQS & $1(1-3)$ & $3(1-5)$ & $2(1-2)$ & $3(1-4)$ & $2(1-3)$ & $1(1-2)$ & $1(1-2)$ & $<0.001 *$ \\
\hline $\begin{array}{l}\text { Modified } \\
\text { DISCERN }\end{array}$ & $1(1-3)$ & $3(1-5)$ & $1(1-2)$ & $3(1-4)$ & $1(1-4)$ & $1(1-4)$ & $1(1-1)$ & $<0.001 *$ \\
\hline \multicolumn{9}{|l|}{$\begin{array}{l}\text { Video source } \\
\quad(n)\end{array}$} \\
\hline Physician & 2 & 3 & 0 & 2 & 1 & 3 & 0 & $<0.001 * *$ \\
\hline $\begin{array}{l}\text { Health per- } \\
\text { sonal }\end{array}$ & 0 & 2 & 0 & 23 & 0 & 0 & 0 & \\
\hline $\begin{array}{l}\text { Health } \\
\text { related } \\
\text { website }\end{array}$ & 0 & 2 & 1 & 2 & 0 & 0 & 2 & \\
\hline Patient & 0 & 0 & 0 & 4 & 0 & 0 & 2 & \\
\hline Trainer & 0 & 1 & 0 & 1 & 0 & 0 & 0 & \\
\hline Tv program & 1 & 0 & 0 & 2 & 1 & 0 & 0 & \\
\hline $\begin{array}{l}\text { Independent } \\
\text { user }\end{array}$ & 0 & 8 & 1 & 0 & 0 & 0 & 0 & \\
\hline $\begin{array}{l}\text { Advertise- } \\
\text { ment }\end{array}$ & 25 & 3 & 3 & 11 & 1 & 12 & 1 & \\
\hline
\end{tabular}

*Kruskal-Wallis test (post hoc: Bonferroni-corrected Mann Whitney $U$ test) $p<0.0045$ is considered as significant

${ }^{* *}$ Chi-square test

Data presented in bold are statistically significant

$V P I$ video power index, GQS Global Quality Score

Table 5 The comparison of Global Quality Scores (GQS) and modified DISCERN median scores with different sources

\begin{tabular}{|c|c|c|c|c|c|c|c|c|c|}
\hline & $\begin{array}{l}\text { Physician } \\
(n=11)\end{array}$ & $\begin{array}{l}\text { Health } \\
\text { personnel } \\
(n=25)\end{array}$ & $\begin{array}{l}\text { Health related } \\
\text { website } \\
(n=7)\end{array}$ & $\begin{array}{l}\text { Patient } \\
(n=6)\end{array}$ & $\begin{array}{l}\text { Trainer } \\
(n=2)\end{array}$ & $\begin{array}{l}\text { TV program } \\
(n=4)\end{array}$ & $\begin{array}{l}\text { Independent } \\
\text { user }(n=10)\end{array}$ & $\begin{array}{l}\text { Adver- } \\
\text { tisement } \\
(n=56)\end{array}$ & $p$ \\
\hline $\begin{array}{r}\text { GQS [median } \\
(\min -\max )]\end{array}$ & $3(1-5)^{\mathrm{a}}$ & $4(1-4)^{b}$ & $3(1-4)$ & $2.5(1-3)^{b}$ & $2.5(2-3)$ & $2(2-3)^{b}$ & $2(1-4)^{b}$ & $1(1-4)^{a, b}$ & $0.016^{*}$ \\
\hline $\begin{array}{l}\text { Modified } \\
\text { DISCERN } \\
{[\text { median }} \\
(\min -\max )]\end{array}$ & $4(1-5)^{\mathrm{a}}$ & $3(1-4)^{b}$ & $3(1-4)$ & $2(1-3)^{b}$ & $2.5(2-3)$ & $2.5(1-3)$ & $2(1-4)^{b}$ & $1(1-4)^{a, b}$ & 0.045* \\
\hline
\end{tabular}

*Kruskal Wallis test (post hoc: ${ }^{\mathrm{a}, \mathrm{b}}$ Bonferroni-corrected Mann Whitney $U$ test), $p$ values presented in bold are statistically significant 
Fig. 3 Video sources (in \%)



\section{Video features}

Video power index (VPI) was found statistically superior for "spa therapy" and "spa treatment" videos which had low quality and reliability scores. The superiority of VPI may be related to the high recognition of the "spa" word among people. In addition, the sources of spa therapy videos were mostly advertisements (60\%). In this respect, our findings are similar to some of the previous studies (Loeb et al. 2019; Erdem and Karaca 2018; Ferhatoglu et al. 2019), suggesting popularity of the videos decreases if uploaded by physicians, academic, or health professionals.

The length of the videos was correlated with both DISCERN and GQS scores. It means that longer videos had higher quality and reliability scores. As we may expect, the longer videos can be more informative, detailing the topic. However, watching a longer video can make people lose interest quickly. Previous studies have shown similar results (Gaş et al. 2019; Ozsoy-Unubol and Alanbay-Yagci 2021).

\section{Video sources}

Most of the videos were sourced from spa centers for advertisement purposes. From this respect, our findings are parallel with the study of Singh et al. (Singh et al. 2012). It is said that advertisements on medical issues may cause misleading information, which provides inaccurate depictions of the disease and its treatment (Stamelou et al. 2011). In a review, it is discussed that the power of YouTube is to change people's minds about controversial issues (Madathil et al. 2015). So, the online information and YouTube content should be checked by physicians regularly to prevent possible disinformation.
The videos prepared by patients who experienced these treatments were not frequent in number. Musculoskeletal disorders consist of problems mainly for the elderly (Makris et al. 2017). On the other hand, Internet usage is still not so prevalent among older people (van Uden-Kraan et al. 2020). So, we can say that the sparseness of patient-based videos on YouTube about spa treatments may be linked with the old age of people who experienced these treatments.

The videos sourced from physicians and non-physician health professionals were also rare. As mentioned before, the underlying cause may be explained by the confusion in terminology defining the treatment methods. Besides, the spa medicine specialty is not common worldwide. Therefore, the fewness of specialists in this field may limit the number of high-quality studies in the literature, which may restrain ranking in guidelines. So, this may decrease awareness of these treatments among other physicians. In fact, we think that it is a vicious circle.

\section{Relevance}

Our results demonstrated that there were a lot of irrelevant videos for the searched terms. Even though we watched 50 videos for each keyword (350 videos total), we only analyzed 121 videos because most of them were irrelevant. The "hydrotherapy" keyword gave us to the most relevant videos $(n=45)$, followed by health resort medicine $(n=28)$, balneotherapy $(n=19)$, balneology $(n=16)$, spa treatment $(n=5)$, and spa therapy $(n=5)$ keywords, respectively. Since the videos on "spa treatments" and "spa therapy" were the least relevant, we think that the "spa" word may not be perceived within medical treatments by YouTube users. In fact, in our search, we saw that the beauty and massage applications were linked with this term on a large scale. Therefore, the 
public perspective should be remembered when using the "spa" word to describe a water treatment modality. There is also a need to demarcate medical spa treatments to enhance their use to promote health.

\section{Limitation}

The videos were evaluated with a single snapshot. Since YouTube is a dynamic platform, the videos' features change at any moment. Besides, we searched the videos in only the English language. Therefore, the searches with different native languages may affect the results. The previous searches also can influence the order of the videos. Since YouTube is not a medical platform, the quality of the videos can be related to the dissemination of advertising information that must be easy to acquire and spread.

\section{Conclusion}

We observed what people would find when searching for water treatments on YouTube. The results showed that the YouTube content linked with water treatments generally lacks quality and reliability. The videos found searching "Hydrotherapy" and "balneotherapy" keywords and the ones uploaded by health professionals provide the best quality and reliability scores. We expect to show the health professionals in this field what information is available to the public about water treatments. We observed a discrepancy in the terms used on YouTube videos, like in scientific studies. So, our study may create a self-inquiry for those interested professionally in balneology.

YouTube can be a tool to spread accurate knowledge about water treatments globally. However, designers of water treatment videos should involve health professionals more often so that their videos' content will better explain the details of medical conditions and interventions. Also, the scientific experts should ensure a consensus in terminology to straighten the awareness of water treatments both for patients and physicians.

\section{References}

Amante DJ, Hogan TP, Pagoto SL, English TM, Lapane KL (2015) Access to care and use of the Internet to search for health information: results from the US National Health Interview Survey. J Med Internet Res 29;17(4):e106.

Antonelli M, Donelli D, Fioravanti A (2018) Effects of balneotherapy and spa therapy on quality of life of patients with knee osteoarthritis: a systematic review and meta-analysis. Rheumatol Int 10(38):1807-1824

Bender T, Karagülle Z, Bálint GP, Gutenbrunner C, Bálint PV, Sukenik S (2005) Hydrotherapy, balneotherapy, and spa treatment in pain management. Rheumatol Int 25(3):220-224
Bernard A, Langille M, Hughes S, Rose C, Leddin D, Veldhuyzen van Zanten S (2007) A systematic review of patient inflammatory bowel disease information resources on the World Wide Web. Am J Gastroenterol 102(9):2070-2077

Bernetti A, Mangone M, Alviti F, Paolucci T, Attanasi C, Murgia M, Di Sante L, Agostini F, Vitale M, Paoloni M (2018) Spa therapy and rehabilitation of musculoskeletal pathologies: a proposal for best practice in Italy. Int J Biometeorol 64(6):905-914

Borroni G, Brazzelli V, Fornara L et al (2013) Clinical, pathological and immunohistochemical effects of arsenical-ferruginous spa waters on mild-to-moderate psoriatic lesions: a randomized placebo-controlled study. Int J Immunopathol Pharmacol 26:495-501

Charnock D, Shepperd S, Needham G, Gann R (1999) DISCERN: an instrument for judging the quality of written consumer health information on treatment choices. J Epidemiol Community Health 53(2):105-111

Cheleschi S, Tenti S, Seccafico I, Gálvez I, Fioravanti A, Ortega E (2021) Balneotherapy year in review 2021: focus on the mechanisms of action of balneotherapy in rheumatic diseases. Environ Sci Pollut Res Int.

Constant F, Collin JF, Guillemin F et al (1995) Effectiveness of spa therapy in chronic low back pain: a randomized clinical trial. J Rheumatol 22:1315-1320

Constant F, Guillemin F, Collin JF et al (1998) Use of spa therapy to improve the quality of life of chronic low back pain patients. Med Care 36:1309-1314

Dönmez A, Karagülle MZ, Tercan N et al (2005) SPA therapy in fibromyalgia: a randomised controlled clinic study. Rheumatol Int 26:168-172

Erdem MN, Karaca S (2018) Evaluating the accuracy and quality of the information in kyphosis videos shared on YouTube. Spine (Phila Pa 1976) 15;43(22):E1334-E1339.

Esen E, Aslan M, Sonbahar BÇ et al (2019) YouTube English videos as a source of information on breast self-examination. Breast Cancer Res Treat 173:629-635

Ferhatoglu MF, Kartal A, Ekici U, Gurkan A (2019) Evaluation of the reliability, utility, and quality of the information in sleeve gastrectomy videos shared on open access video sharing platform YouTube. Obes Surg 29(5):1477-1484

Fioravanti A, Giannitti C, Bellisai B et al (2012) Efficacy of balneotherapy on pain, function and quality of life in patients with osteoarthritis of the knee. Int J Biometeorol 56:583-590

Forestier R, Desfour H, Tessier J-M et al (2010) Spa therapy in the treatment of knee osteoarthritis: a large randomised multicentre trial. Ann Rheum Dis 69:660-665

Franke A, Reiner L, Pratzel HG et al (2000) Long-term efficacy of radon spa therapy in rheumatoid arthritis - a randomized shamcontrolled study and follow-up. Rheumatology 39:894-902

Franke A, Reiner L, Resch KL (2007) Long-term benefit of radon spa therapy in the rehabilitation of rheumatoid arthritis: a randomised, double-blinded trial. Rheumatol Int 27:703-713

Garg N, Venkatraman A, Pandey A et al (2015) YouTube as a source of information on dialysis: a content analysis. Nephrology (carlton) 20:315-320

Gaş S, Zincir ÖÖ, Bozkurt AP (2019) Are YouTube videos useful for patients interested in botulinum toxin for bruxism? J Oral Maxillofac Surg 77(9):1776-1783

Gul M, Diri MA (2019) YouTube as a source of information about premature ejaculation treatment. J Sex Med 16(11):1734-1740

Gutenbrunner C, Bender T, Cantista P, Karagülle Z (2010) A proposal for a worldwide definition of health resort medicine, balneology, medical hydrology and climatology. Int J Biometeorol 54(5):495-507

Huang A, Seité S, Adar T (2018) The use of balneotherapy in dermatology. Clin Dermatol 36(3):363-368 
Kardeş S (2019a) Seasonal variation in the internet searches for gout: an ecological study. Clin Rheumatol 38:769-775

Kardeş S (2019b) Seasonal variation in the internet searches for psoriasis. Arch Dermatol Res 311:461-467

Kardeş S (2021) Public interest in spa therapy during the COVID-19 pandemic: analysis of Google Trends data among Turkey. Int $\mathbf{J}$ Biometeorol 65(6):945-950

Knösel M, Jung K (2011) Informational value and bias of videos related to orthodontics screened on a video-sharing Web site. Angle Orthod 81(3):532-539

Kocyigit BF, Nacitarhan V, Koca TT, Berk E (2019) YouTube as a source of patient information for ankylosing spondylitis exercises. Clin Rheumatol 38(6):1747-1751

Leaute-Labreze C, Saillour F, Chene G et al (2001) Saline spa water or combined water and UV-B for psoriasis vs conventional UV-B: lessons from the Salies de Bearn randomized study. Arch Dermatol 137:1035-1039

Loeb S, Sengupta S, Butaney M, Macaluso JN Jr, Czarniecki SW, Robbins R, Braithwaite RS, Gao L, Byrne N, Walter D, Langford A (2019) Dissemination of misinformative and biased information about prostate cancer on YouTube. Eur Urol 75(4):564-567

Maccarone MC, Kamioka H, Cheleschi S, Tenti S, Masiero S, Kardeş S (2021) Italian and Japanese public attention toward balneotherapy in the COVID-19 era. Environ Sci Pollut Res Int 28(43):61781-61789

Madathil KC, Rivera-Rodriguez AJ, Greenstein JS, Gramopadhye AK (2015) Healthcare information on YouTube: a systematic review. Health Informatics J 21(3):173-194

Makris UE, Misra D, Yung R (2017) Gaps in aging research as it applies to rheumatologic clinical care. Clin Geriatr Med 33(1):119-133

Mavragani A, Ochoa G (2019) Google Trends in infodemiology and infoveillance: methodology framework. JMIR Public Health Surveill 29;5(2):e13439.

Ozsoy-Unubol T, Alanbay-Yagci E (2021) YouTube as a source of information on fibromyalgia. Int J Rheum Dis 24(2):197-202

Sajadi KP, Goldman HB (2011) Social networks lack useful content for incontinence. Urology 78(4):764-767
Singh AG, Singh S, Singh PP (2012) YouTube for information on rheumatoid arthritis-a wakeup call? J Rheumatol 39:899-903

Stamelou M, Edwards MJ, Espay AJ, Fung VS, Hallett M, Lang AE, Tijssen MA, Bhatia KP (2011) Movement disorders on YouTube-caveat spectator. N Engl J Med 22;365(12):1160-1.

Stier-Jarmer M, Kus S, Frisch D, Sabariego C, Schuh A (2015) Health resort medicine in non-musculoskeletal disorders: is there evidence of its effectiveness? Int J Biometeorol 59(10):1523-1544

Teng Y, Bi D, Xie G, Jin Y, Huang Y, Lin B, An X, Feng D, Tong Y (2017) Dynamic forecasting of Zika epidemics using Google Trends. PLoS One 12:e0165085.

Tolu S, Yurdakul OV, Basaran B, Rezvani A (2018) English-language videos on YouTube as a source of information on self-administer subcutaneous anti-tumour necrosis factor agent injections. Rheumatol Int 38(7):1285-1292

van Tubergen A, Landewé R, van der Heijde D, et al (2001) Combined spa-exercise therapy is effective in patients with ankylosing spondylitis: a randomized controlled trial. Arthritis Rheum 45:430-438

van Uden-Kraan CF, Drossaert CH, Taal E, Smit WM, Moens HJ, Siesling S, Seydel ER, van de Laar MA (2009) Health-related Internet use by patients with somatic diseases: frequency of use and characteristics of users. Inform Health Soc Care 34(1):18-29

van Uden-Kraan CF, Jansen F, Lissenberg-Witte BI, Eerenstein SEJ, Leemans CR, Verdonck-de Leeuw IM (2020) Health-related and cancer-related Internet use by patients treated with total laryngectomy. Support Care Cancer 28(1):131-140

Verhagen AP, Cardoso JR, Bierma-Zeinstra SMA (2012) Aquatic exercise \& balneotherapy in musculoskeletal conditions. Best Pract Res Clin Rheumatol 26:335-343

Yang S, Kou SC, Lu F, Brownstein JS, Brooke N, Santillana M (2017) Advances in using Internet searches to track dengue. PLoS Comput Biol 13:e1005607.

YouTube for Press. https://www.youtube.com/about/press/. Accessed April 20, 2020. 